\title{
Modeling decentralized systems for energy savings based on detailed local thermal comfort calculations
}

\author{
Katharina Boudier ${ }^{1}$, Sabine Hoffmann ${ }^{1}$ \\ ${ }^{1}$ TU Kaiserslautern, Kaiserslautern, Germany
}

\begin{abstract}
Local thermal comfort plays a growing role not only for occupant satisfaction but also in the energy performance of a building. Decentralized heating and cooling systems can be used to enhance thermal comfort for building occupants at low energy cost. This paper presents a newly developed controller for combined, central and decentralized systems inside the building simulation software ESP-r. It controls decentralized systems and the central HVAC system based on local and overall thermal sensation and comfort values, the output of a 65-node thermophysiology, sensation and comfort model (PhySCo). The decentralized system modelled is a movable partition for local cooling or heating called Thecla. This study shows that using the combined, central and decentralized, systems could reduce the total energy consumption from cooling and heating systems by $15 \%$ over a year, while maintaining thermal comfort at an acceptable level.
\end{abstract}

\section{Introduction}

Thermal comfort plays a growing role in the built environment. The maintenance of thermal comfort inside office buildings often comes with a high energy demand. There is evidence that decentralized systems can play a crucial role in providing thermal comfort to building occupants (Boudier and Hoffmann, 2016; Hoffmann and Boudier, 2016; Kimmling and Hoffmann, 2017b; Luo et al., 2018) and at the same time they can lead to energy savings through an extended room temperature deadband (Hoyt et al., 2015). These low power decentralized systems can extend the comfortable room temperature deadband as the occupants still feel comfortable with higher or cooler overall room temperature. With these systems they have the opportunity to heat or cool their immediate thermal environment by themselves.

Up to now, far too little attention has been paid to applying decentralized systems in building simulation software. Perhaps this is because of the lack of alternatives to calculate detailed local thermal comfort values in the building simulation. Most building simulation software considers only Fanger's PMV/PPD (Predicted Mean Vote)/(Predicted Percentage of Dissatisfied) (Fanger, 1970). In general PMV is inadequate for asymmetric conditions (Tanabe et al., 2000) and under transient conditions as it considers one overall value only. However, the environmental conditions in buildings are usually asymmetric (e.g. large glazing area, radiant heating/ cooling panels, decentralized systems). For these conditions a detailed physiology, sensation and comfort model "PhySCo" (Physiology, Sensation, Comfort) is recommended (Boudier et al., 2016; Ganji Kheybari et al., 2018). "PhySCo" allows for the calculation of body temperatures, local and overall thermal sensation and comfort values for 16 individual body parts.

This paper is based on the coupling of the building simulation software ESP-r (ESRU) with "PhySCo" (Boudier et al., 2016) in consideration of a control logic of decentralized systems depending on thermal comfort and local thermal sensation values.

\section{PhySCo}

PhySCo is a standalone program that can be coupled with other tools. It contains a detailed 65-node physiology model which is coupled with a sensation and comfort model. The model handles asymmetric environments and transient conditions and considers personal parameters such as clothing value and activity level. It takes into account 16 local values of the five environmental parameters: dry bulb temperature, mean radiant temperature, air velocity, relative humidity and solar radiation. PhySCo calculates the skin and core temperatures, local and overall sensation and comfort values for the 16 body parts as well as the whole body.

The physiology model of PhySCo is based on prominent experimental and numerical work in the field of thermoregulatory models for the human body (Stolwijk, 1971; Tanabe et al., 2002; Huizenga et al., 2001; Hoffmann et al., 2012). The physiology model considers the physiological processes through a complex set of equations in which the human body is represented by 16 body parts, each of them consisting of 4 layers (core, muscle, fat, skin) and a blood flow node. This model is linked to a model based on an empirical study (Zhang et al., 2010c, 2010a, 2010b) which calculates local sensation and comfort values for each body segment along with overall sensation and comfort values. Local thermal sensation is calculated based on local skin values, whereas local thermal comfort is calculated based on local thermal sensation and overall thermal sensation (Zhang et. al., 2010a, 2010b, 2010c). 


\section{Coupling of PhySCo with ESP-r}

In previous work PhySCo was coupled with the building simulation software ESP-r. The idea and the first approach is shown in (Boudier et al., 2016). The building simulation controller regulates the room temperature setpoints of a zone based on overall sensation and overall comfort of a detailed manikin located in the zone. The idea is to maintain a wide temperature deadband while the manikin is experiencing the desired comfort level and adapt the lower and upper temperature setpoints of the deadband if the comfort level drops.

\section{(Wo)Man in Cube}

For the detailed calculation of local sensation and comfort values, the mean radiant temperature (MRT) is essential. The calculation of local MRT values for the 16 body parts of PhySCo is based on a detailed view factor calculation method. Inside the coupling process the approach "(Wo)Man in Cube” (Ganji Kheybari et al., 2018) was used to calculate detailed MRT values.

"(Wo)Man in Cube" is a combined method using two instances of view factor calculation Vf1, Vf2 (Figure 1). It uses a detailed manikin with 16 distinct body parts (to be used as input for PhySCo), which is placed inside three "MRT cubes" at a desired location in the ESP-r zone (Figure 1).
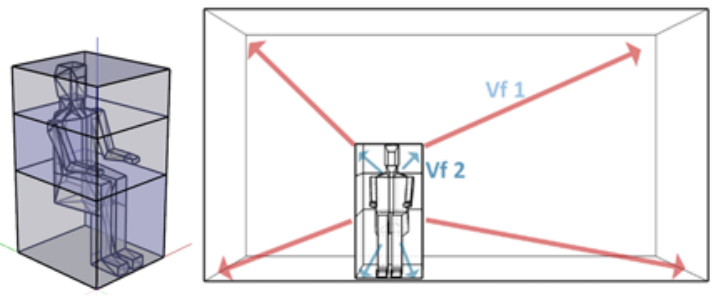

Figure 1: Left: Three MRT cubes and the seated manikin inside, right: (Wo)Man in Cube approach with a combined view factor calculation

The calculation of the 16 local MRT values for the body parts required by PhySCo starts with a view factor calculation (Vf 1) between the three MRT cubes and the room geometry in ESP-r (Raytracing method). The method is straightforward and fast. The "surface temperatures" of the MRT cubes were used in the local MRT calculation for the 16 body parts. With a precalculated set of view factors (Vf 2) between the manikin and the three MRT cubes, the MRT values for the body parts can be calculated. For different manikins and positions, different precalculated sets of view factors (standing, sitting) were generated. These precalculated sets of view factors were calculated with the semianalytical method of the open source software View3D (Walton \& Pye).

This paper shows the new approach of a building simulation controller called "Coupling with PhySCo" with the option of using additional decentralized systems in ESP-r to control the decentralized systems and/or any thermal zone. The modelled decentralized system is a movable partition for local cooling or heating called Thecla (Thermoelectric Cooling partition with Active storage) (Kimmling and Hoffmann, 2016, 2017a, 2017b). It activates a cold or warm surface with peltier elements.
Thecla provides three individually controllable zones which target 1) the head, 2) the middle part of the body and 3) feet and legs.

The control of Thecla inside the building simulation is based on local sensation, overall sensation values and on overall comfort. The central HVAC system is controlled by adjusting the deadband (upper temperature setpoint for cooling, lower temperature setpoint for heating) in order to minimize energy consumption and maintain overall thermal comfort in a positive range.

\section{Methods}

\section{Implementation of Thecla}

The implementation of the Thecla controller within the controller "Coupling with PhySCo" is based on the "(Wo)Man in Cube" approach. The approach is particularly useful as the three zones can be controlled individually based on the local sensation values of head, left/right shoulder or back and pelvis. The head and the pelvis have an especially high influence on overall comfort in warm (head) and cold (pelvis) environments (Zhang, 2003).

The approach of Thecla is implemented by overwriting the "surface" temperatures of the "(Wo)Man in Cube" cubes, which essentially act as MRT sensors. Thecla can be used for heating and/or cooling with two constant surface temperatures of $35^{\circ} \mathrm{C}$ for heating mode and $18^{\circ} \mathrm{C}$ for cooling mode. If any of the zones is not required, the surface temperature will be overwritten with the actual dry bulb temperature (DB).

The heating and cooling effect of Thecla is based on longwave radiation. A lower surface temperature than the skin or clothing temperature of the human body yields a cooling effect. For the heating mode, the surface temperature of Thecla is close to the skin or clothing temperature, so that the radiative heat loss is reduced and the body feels warmer (compared to not using the heating mode).

The method of using the MRT cubes to represent Thecla requires the calculation of a new set of view factors (Vf 2) according to the "(Wo)Man in Cube" approach if the distance of Thecla to the person is changed.

Thecla requires an energy demand of $16 \mathrm{~W}$ for cooling and $12 \mathrm{~W}$ for heating per zone.

\section{ESP-r controller with Thecla}

In the following we explain how the controller acts based on sensation and comfort values. Sensation in terms of being warm or cold can be shown on a scale ranging from -4 (very cold) to +4 (very hot) over 0 (neutral) (Zhang et al., 2010c). Thermal comfort, the state of mind that expresses satisfaction with the thermal environment, (ASHRAE, 1997) can be shown on a scale ranging from 4 (very uncomfortable) to +4 (very comfortable), without 0 (neutral) (the manikin feels either comfortable or uncomfortable) (Zhang et al., 2010a).

The newly developed controller "Coupling with PhySCo" is an adapted basic ideal controller BCL00, located in the bcfunc.F of ESP-r (ESRU). In a subroutine of the 
"Coupling with PhySCo" controller, the control of Thecla can be selected as an additional control (based on the logic in Figure 2). The physiology model uses the environmental input of Mean Radiant Temperature (MRT), Dry Bulb Indoor Air Temperature (DB), and Room Humidity, which are calculated for every timestep in ESP-r. The metabolic rate of the manikin and the air velocity are defined before the the simulation starts. The clothing values for the 16 body parts can be obtained for every timestep in combination with the "dynamic clothing model” (Rida and Hoffman, 2019) or as fixed input values for a summer or winter clothing file.

The controller adapts the surface temperatures of Thecla based on overall $S_{o}$ and local sensation $S_{l}$ (Table 1) for the next time step. If required the heating and cooling setpoints for the central HVAC system are adapted depending on the values of overall comfort $C_{o}$ and overall sensation $S_{o}$. The setpoints are variable and start with a wide deadband. If the decentralized systems are used and a positive comfort level is achieved, a smoothing condition is used. This brings the setpoints for the central HVAC system gently back to their initial values (Figure 2).

\section{Local sensation setpoints for the controller}

The following table shows the local sensation setpoints (SP) to define the Thecla zone's surface temperatures (Temp) for heating, cooling or in the case that Thecla is not activated. In the last case DB is used. As the pelvis is sensitive to cold environments (Zhang et al., 2010c), the cooling setpoint was defined higher (SP 1.0) than for the other body parts. The setpoints for heating and cooling show different values because the body parts have different sensitivity to warmth and cold (Zhang et al. 2010 a,b,c).

Table 1: Local sensation setpoints (SP) that define the Thecla surface temperature (Temp $\left.\left[{ }^{\circ} \mathrm{C}\right]\right)$

\begin{tabular}{|l|l|l|l|l|l|l|c|}
\hline \multicolumn{7}{|c|}{ Thecla on the Left } \\
\hline Zone & $\begin{array}{l}\text { Controlling } \\
\text { Body part }\end{array}$ & $\begin{array}{l}\text { SP for } \\
\text { cooling }\end{array}$ & $\begin{array}{l}\text { Temp } \\
{\left[{ }^{\circ} \mathrm{C}\right]}\end{array}$ & $\begin{array}{l}\text { SP for not } \\
\text { using }\end{array}$ & $\begin{array}{l}\text { Temp } \\
{\left[{ }^{\circ} \mathrm{C}\right]}\end{array}$ & $\begin{array}{l}\text { SP for } \\
\text { heating }\end{array}$ & $\begin{array}{l}\text { Temp } \\
{\left[{ }^{\circ} \mathrm{C}\right]}\end{array}$ \\
\hline Top & Head & $\geq 0.8$ & 18 & $-1<S_{l}<0.8$ & DB & $S_{l} \leq-1$ & 35 \\
\hline Middle & $\begin{array}{l}\text { Left } \\
\text { shoulder }\end{array}$ & $\geq 0.8$ & 18 & $-1<S_{l}<0.8$ & DB & $S_{l} \leq-1$ & 35 \\
\hline Bottom & Pelvis & $\geq 1.0$ & 18 & $-1<S_{l}<1.0$ & DB & $S_{l} \leq-1$ & 35 \\
\hline
\end{tabular}

Figures 3 and 4 illustrate how the Thecla zones are performing based on the logic. Figure 3 shows the controlling sensation values and Figure 4 the corresponding activated Thecla zones.

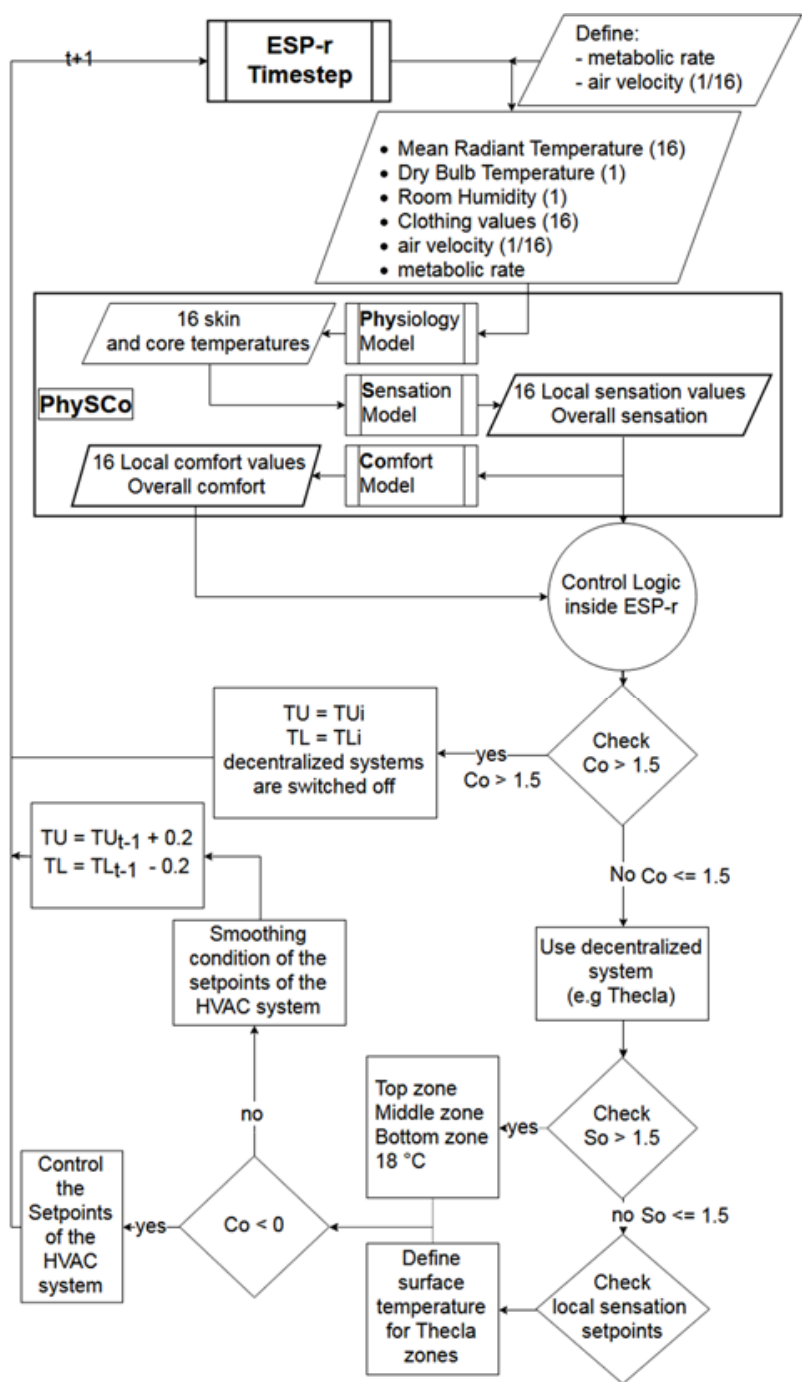

Figure 2: Flowchart of the logic inside the controller

Based on the logic, the Top zone will be used for cooling if the local sensation value of the head (Sl_head) exceeds 0.8 . The middle and the bottom zone are not activated most of the time. Only on two occasions are they also used for cooling because at that time overall sensation $S_{o}$ reached a value above 1.5 . In this case all zones are switched on for cooling (see also Figure 2).

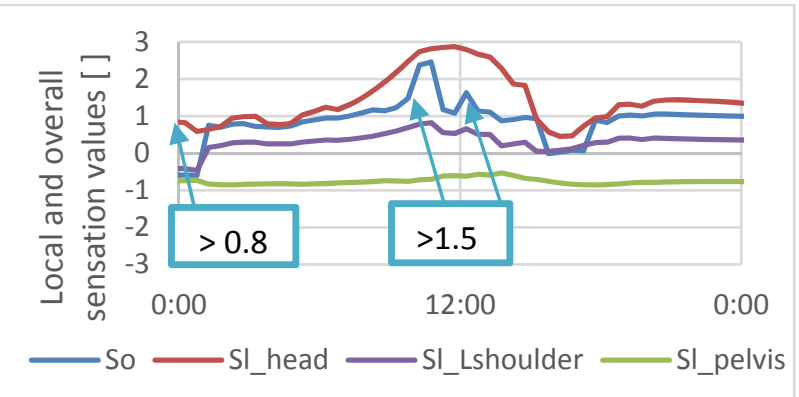

Figure 3: Controlling sensation values, one day in June 


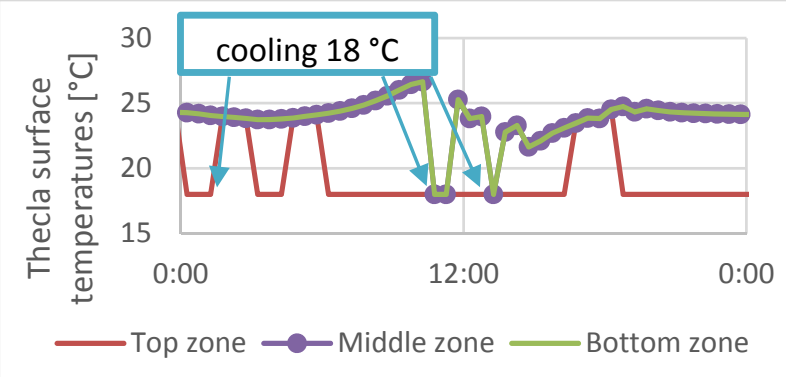

Figure 4: Activated Thecla (mostly Top zone) for cooling $\left(18^{\circ} \mathrm{C}\right)$, one day in June

\section{Room geometry and Manikin}

A simple shoebox model with a length of $5.0 \mathrm{~m}$, width of $3.0 \mathrm{~m}$ and height of $2.7 \mathrm{~m}$ was used for the simulations in ESP-r. The window to wall ratio is $30 \%$ with one window facing the south.

The detailed manikin geometry originates from the open source software ladybug (Ladybug Tools). The surface areas of the single body segments match the surface areas of the physiology model used inside PhySCo with a total surface area of $1.87 \mathrm{~m}^{2}$.

\section{Simulation parameters}

Table 2 shows the simulation parameters such as clothing factor, metabolic rate, as well as the upper and lower setpoints of the deadband, (TU, TL) which were kept constant. When Thecla was used, the distance between Thecla and the arm of the manikin was kept at $10 \mathrm{~cm}$.

Table 2: Simulation parameters

\begin{tabular}{|c|c|c|c|c|c|c|}
\hline 苞 & 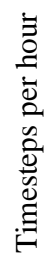 & 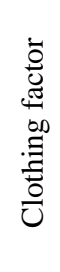 & 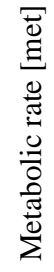 & $\begin{array}{l}\underset{0}{U} \\
\underset{\ominus}{0}\end{array}$ & $\begin{array}{l}\varpi \\
o \\
\vdots \\
己\end{array}$ & 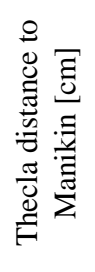 \\
\hline $\begin{array}{l}\text { with } \\
\text { Thecla }\end{array}$ & 2 & 0.5 & 1.0 & 18 & 28 & 10 \\
\hline $\begin{array}{l}\text { without } \\
\text { Thecla }\end{array}$ & 2 & 0.5 & 1.0 & 18 & 28 & - \\
\hline
\end{tabular}

\section{Results}

The following section shows the comparison of 1) adaptation of the deadband, 2) energy demand 3) sensation and comfort values based on simulation results for the months of August and November.

\section{Adaptation of the deadband}

The simulations show the adaptation of the comfort deadband which consist of a lower setpoint temperature (TL) and an upper setpoint temperature (TU). The deadband was chosen with initial setpoints of $\mathrm{TL}=18^{\circ} \mathrm{C}$ and $\mathrm{TU}=28^{\circ} \mathrm{C}$ which represents a relatively broad range with the intention of reducing energy demand. Figure 5 presents the setpoint variation along with the dry bulb temperature for both cases, with and without using
Thecla. DB is regulated by the adaptation of the comfortable deadband and should always be between TL and TU.

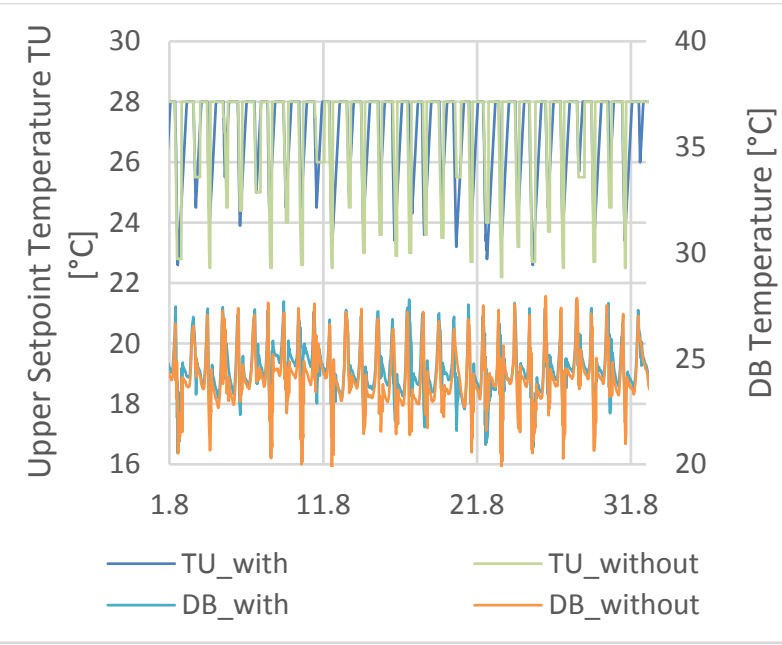

Figure 5: Adaptation of the deadband in August,

Comparison of the cases with and without Thecla

In order to assess the impact on the deadband adaptation when using the controller with Thecla, Figure 5 shows results for a summer month (August). It can be noted that the upper set point temperature, which activates the central cooling system, is usually higher when using Thecla compared to without Thecla, which indicates that the manikin is still comfortable. For the case with Thecla the smoothing condition is visible in diagonal lines. There are a few days where the TU_with exceeds TU_without and shows lower setpoints. That happened due to the fact that the DB_without of the previous day was lower than DB_with. On these few occasions, higher sensation values activated the adaptation of TU_with. However, TU_without is most on the days below the setpoint of TU_with. DB reaches values of up to $27.5^{\circ} \mathrm{C}$ in both cases.

During a winter month in November (Figure 6) the effect of using the decentralized system on the deadband adaptation is more clear.

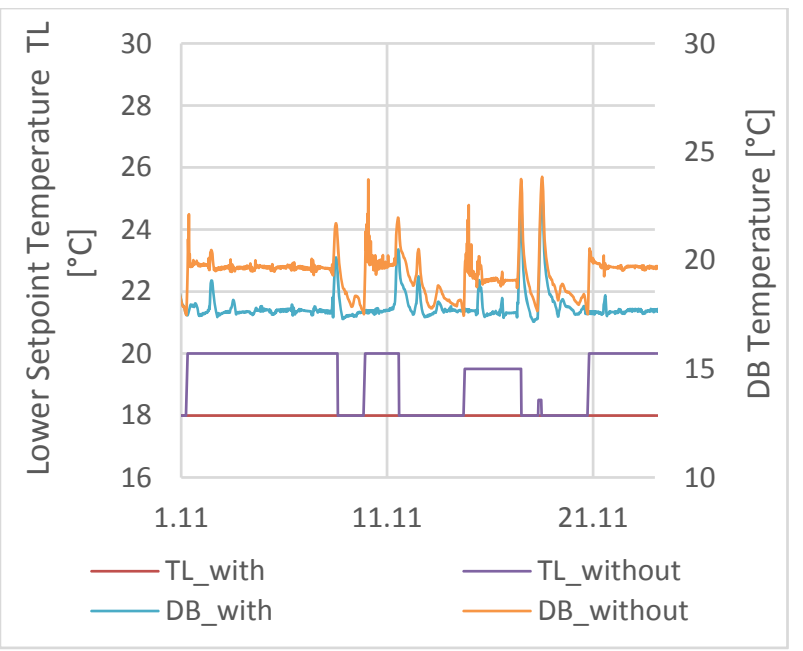

Figure 6: Adaptation of the deadband in November, Comparison of the cases with and without Thecla 
For the case without Thecla the graph shows an adaptation of the lower setpoint $\mathrm{TL}$ to $20^{\circ} \mathrm{C}$. On some days the setpoint temperatures were set back to the initial value of $18^{\circ} \mathrm{C}$. The setpoint temperature for the case with Thecla was maintained at the initial setpoint temperature of $18^{\circ} \mathrm{C}$ during the whole month. The dry-bulb temperature in the case when Thecla was used was significantly lower than for the case without Thecla.

The adaptation of the deadband has influence on the energy demand of the HVAC system.

\section{Energy demand}

To compare the energy demand of the case with Thecla and the case without Thecla, the graphs show the cool injection in August and the heat injection in November for the controller which is using Thecla (Heatinj_with, Coolinj_with) and the controller not using Thecla (Heatinj_without, Coolinj_without).

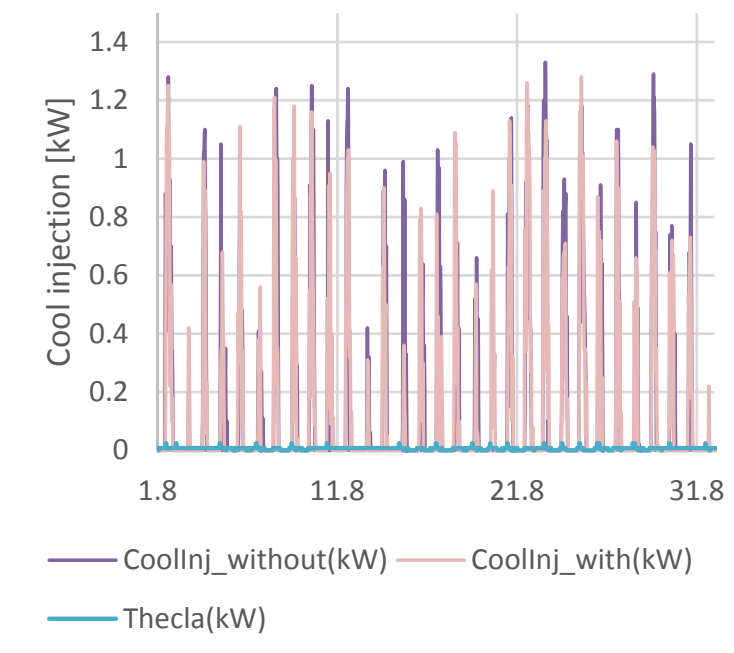

Figure 7: Energy demand in August, Comparison of cooling injection with and without Thecla

Figure 7 shows that the energy demand of the HVAC system without Thecla is higher than when it is used. However, the difference between the two cases is not always significant. When Thecla was used, the HVAC system was still frequently required and occasionally the energy demand exceeded that of the case without Thecla. That was due to a lag in the central system controller and the dry bulb temperature. Because of a higher dry bulb temperature for the case with Thecla, the sensation level rose in some occasions and lead to the adaptation of the upper setpoint temperature (see explanation in Figure 5).

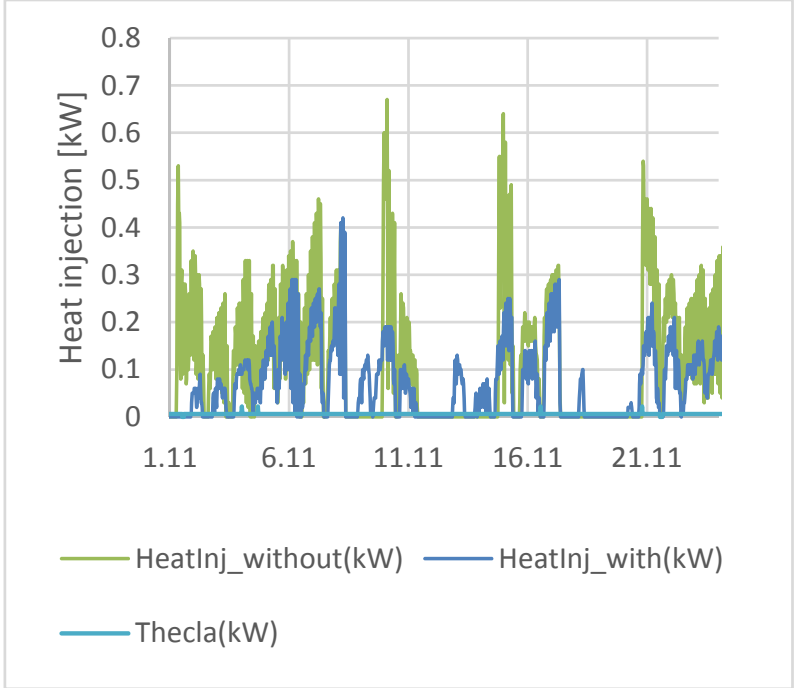

Figure 8: Energy demand in November, Comparison of heat injection with and without Thecla

For the month of November (Figure 8) the simulation results show that the energy demand with Thecla is significant lower than the energy demand without Thecla. Thecla was used at least with one zone with power of 12 $\mathrm{W}$. Occasionally more zones were used.

Table 3 below compares the values of the annual energy demand of the central HVAC with and without Thecla when only the central HVAC was used. The energy demand for Thecla is distributed into the three Thecla zones: head, core, and lower body. Energy savings of around $15 \%$ can be reached with the combined control logic of Thecla and HVAC systems compared to the control logic of just using the central HVAC system.

Table 3: Comparison of the annual energy demand with Thecla and HVAC and with only HVAC

\begin{tabular}{|c|c|c|c|c|c|c|c|}
\hline & \multirow[b]{2}{*}{ 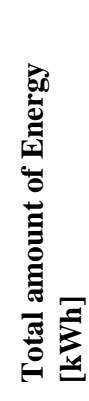 } & \multirow[b]{2}{*}{ 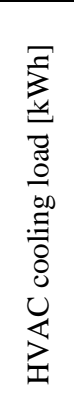 } & \multirow[b]{2}{*}{ 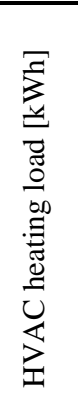 } & \multicolumn{4}{|c|}{ Thecla } \\
\hline & & & & 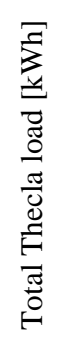 & 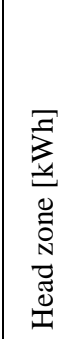 & 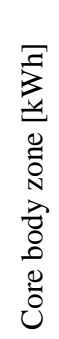 & 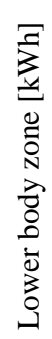 \\
\hline $\begin{array}{c}\text { Thecla and } \\
\text { HVAC }\end{array}$ & 1398 & 649 & 653 & 96 & 36 & 2 & 58 \\
\hline $\begin{array}{c}\text { just central } \\
\text { HVAC }\end{array}$ & 1653 & 728 & 925 & & Withol & The & \\
\hline $\begin{array}{c}\text { Reduction } \\
\text { in energy } \\
\text { demand }\end{array}$ & $\begin{array}{c}15.4 \\
\%\end{array}$ & $\begin{array}{c}10.1 \\
\%\end{array}$ & $\begin{array}{c}29,4 \\
\%\end{array}$ & & & & \\
\hline
\end{tabular}




\section{Sensation and comfort values}

This section provides the comparison of overall sensation $\left(S_{o}\right)$ and overall comfort $\left(C_{o}\right)$.

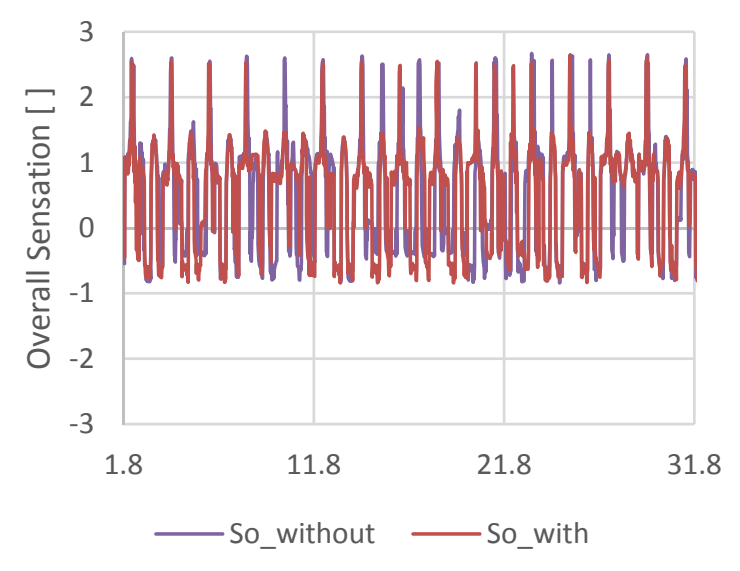

Figure 9: Sensation values in August, Comparison of the cases with and without Thecla

Overall sensation is for both scenarios with and without Thecla similar in August. Sometimes overall sensation values exceed a value of 2 .

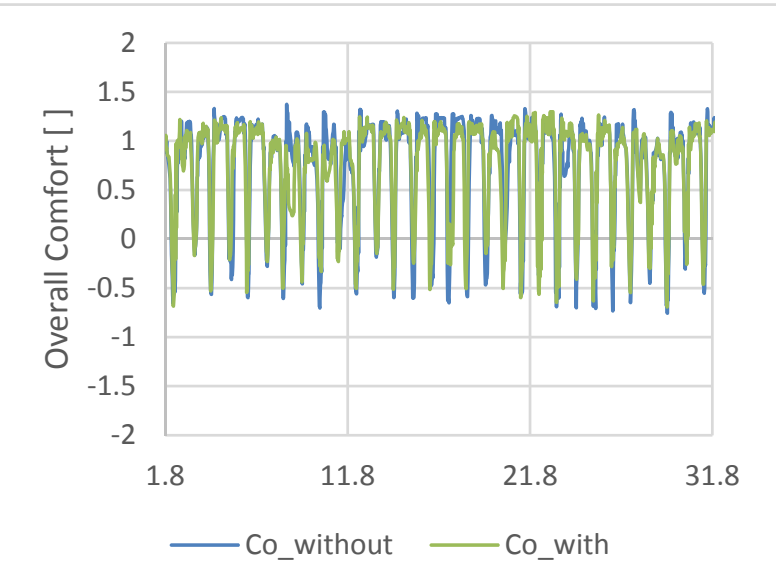

Figure 10: Comfort values in August; Comparison of the cases with and without Thecla

The results for August in Figure 10 illustrate that overall comfort values are in the same range for the cases with and without Thecla. Overall comfort values range between -0.7 and 1.3 in both cases.

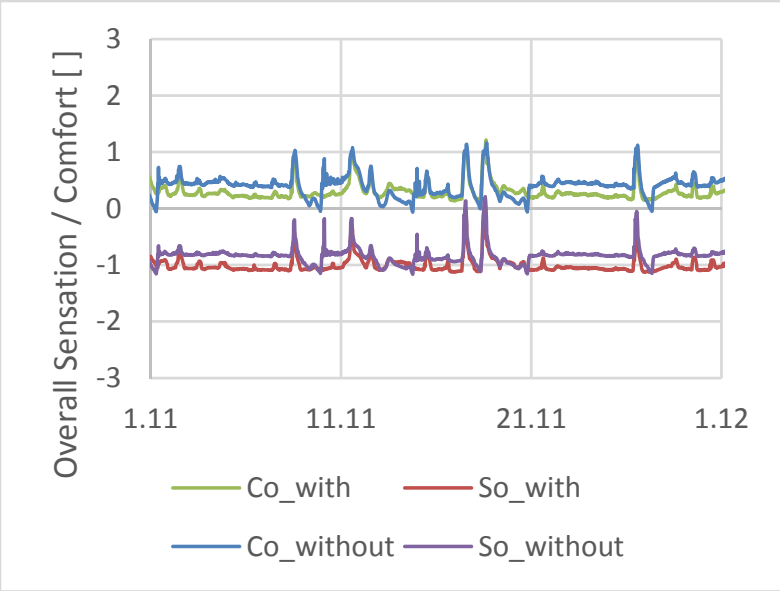

Figure 11: Sensation and comfort values in November, Comparison of the cases with and without Thecla

Figure 11 represents the simulation for November. The overall sensation values are between $0-0.5$ and -1 most of the time. This leads to comfortable conditions and overall comfort values in the positive range.

The boxplots below show the comparison of overall sensation (Figure 12) and overall comfort values (Figure 13) throughout the year. The two cases, with Thecla and without Thecla, are compared.

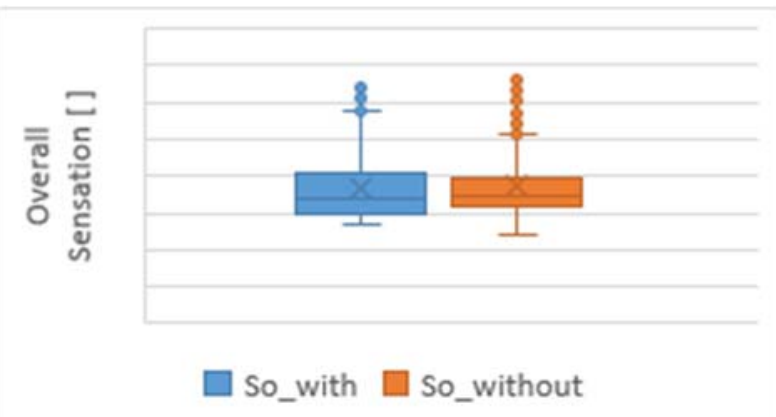

Figure 12: Comparison of Overall Sensation over the whole year, with and without Thecla

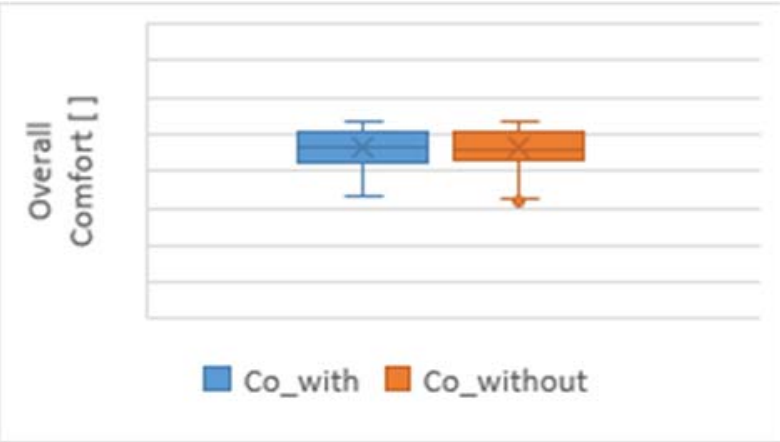

Figure 13: Comparison of Overall Comfort over the whole year, with and without Thecla

The boxplots show more outliers in overall sensation when not using Thecla compared to when Thecla is used. 
The results for overall comfort when Thecla was used show that the median is clearly in the positive range and a bit higher than the case where just the central HVAC system was used. The whiskers for the case with Thecla are less negative.

\section{Discussion}

The intention of this study was to achieve a reduction in energy consumption in buildings by using a building controller with a localized heating and cooling system to support a wide deadband of comfortable room temperatures. The results from the simulations demonstrated that a noticeable reduction in the energy consumption of the central HVAC system can be achieved with an increased deadband. Moreover, the energy demand of the central HVAC system could be reduced while keeping the comfort values at the same level.

Figure 8 shows that the required power of Thecla fluctuates in August from $16 \mathrm{~W}$ to $48 \mathrm{~W}$. Sometimes all zones are switched on because overall sensation rises beyond 1.5 (see also Figures 2 and 3). In this case all three zones were used for cooling. The level of 1.5 has been selected, as high sensation levels lead to votes of discomfort. To overcome a high sensation level this condition was chosen to directly react at all body parts.

High indoor temperatures occasionally lead to overall sensation values over 2 and consequently to votes of discomfort (Figures 9, 10). The head is very sensitive to warm conditions. In this case the cooling condition of Thecla is not enough and a further decentralized system is recommended. However, overall comfort in both cases ranges between -0.5 to 1.0 . With Thecla, the energy demand could be lowered by $1.6 \%$ while maintaining the same level of comfort. The votes of slight discomfort cause the control logic to switch to using the central HVAC system. The logic could be changed back to an abrupt change of TU to the initial setpoint TUi, instead of the smoothing condition for the case with Thecla. The smoothing condition requires further investigation in terms of thermal comfort and further possible reduction of energy demand.

For the simulation in November the deadband for the logic with Thecla could be maintained consistently at the initial setpoint, whereas the lower setpoint for the case without Thecla was adapted several times (Figure 6). The dry bulb temperatures are also different for the control logic with Thecla and without Thecla in Figure 6. Lower dry bulb temperatures in winter are accepted with the decentralized system and the same comfort level can be maintained (see Figure 11). The overall sensation values are between -0.5 and 1 most of the time. This still leads to comfortable conditions and overall comfort values within a positive range (Figure 11). The maintenance of the initial setpoint TLi leads therefore to a significantly lower heating demand in the simulation with Thecla compared to the simulation without Thecla (Figure 8).
As expected the reduction of the annual energy demand is around $15 \%$ for the combination of the decentralized system with the central HVAC system (Table 3 ). The decentralized system can support a positive comfort value where the HVAC system is less required. The heating load of the central HVAC system could be reduced substantially by $270 \mathrm{kWh}$. The cooling load could also be lowered by $70 \mathrm{kWh}$. For the summer conditions solar influence and high indoor temperatures play a crucial role. In this case further decentralized systems could be helpful to minimize the heating load for the head, which is sensitive to warm conditions (Zhang, 2003) and lead to a further reduction of the cooling demand of the HVAC system.

\section{Conclusion}

Decentralized systems are a great way to decrease the energy consumption of the central HVAC system and provide a positive level of thermal comfort for building occupants in new and retrofit buildings. The newly developed controller, which acts based on local sensation, overall sensation and overall comfort values, is a helpful tool to calculate the possible reduction in energy demand and the thermal comfort of occupants when using decentralized systems such as Thecla.

For the winter months the building simulation controller "Coupling with PhySCo" in combination with the decentralized system Thecla, can achieve clear results in terms of the desired reduction in energy demand as well as for positive comfort values. For the month of November, the deadband adaptation for the case without Thecla was variable. For the case with Thecla the lower setpoint TL could be maintained at a constant value at the initial setpoint temperature and the heating demand could get minimized.

During the summer months the controller in combination with Thecla can also decrease energy demand. For high indoor temperatures some additional decentralized systems are suggested, as for example a fan for the head region, which is particularly sensitive to warmth (Zhang, 2003), (Luo et al., 2018). However, throughout the month the simulation with Thecla achieved a lower cooling consumption than the simulation without Thecla.

Overall, the results indicate that the achieved comfort level and the reduction in energy demand of the central HVAC depend strongly on the logic used. Higher comfort values can be achieved by changing the control logic. In this paper the focus was to reduce the energy demand with regard to a positive comfort level.

\section{Outlook}

In the future this coupling controller will be accessible to the research community as part of a new ESP-r release as well as for designers and engineers to plan its possible usage and assess the benefits of decentralized systems. Besides Thecla an office chair with heating and cooling functions will then be available in the controller. 


\section{References}

ASHRAE (1997) ASHRAE Fundamentals Handbook. Chapter 8. Thermal Comfort. American Society of Heating, Refrigeration and Air-Conditioning Engineers. Atlanta (USA).

Boudier K., Fiorentini M., Hoffmann S., et al. (2016). Coupling a thermal comfort model with building simulation for user comfort and energy efficiency. Proceedings of the Central European Symposium on Building Physics (CESBP) and BauSIM. Dresden (Germany), September 2016, 481-486.

Boudier K., Hoffmann S. (2016). Heated and cooled chairs for office use in: conference proceedings ICHES2016. Nagoya (Japan), October/November 2016.

ESRU. ESP-r. https://github.com/ESP-rCommunity/ESPrSource (14.12.2018).

Fanger P. O (1970). Thermal comfort. Analysis and applications in environmental engineering. New York, N.Y.: McGraw-Hill. New York.

Ganji Kheybari A., Boudier K., Hoffmann S. (2018). Using a "MRT Manikin" To Assess Local and Overall Thermal Sensation and Comfort in: Proceedings of BauSIM 2018. Karlsruhe (Germany), September 2018.

Hoffmann S., Boudier K. (2016). A new approach to provide thermal comfort in office buildings: A field study with heated and cooled chairs. Proceedings of Indoor Air Quality Ventilation \& Energy Conservation in Buildings (IAQVEC). Incheon Songdo (Republic of Korea), October 2016.

Hoffmann S., Jedek C., Arens E. (2012). Assessing thermal comfort near glass facades with new tools. Building Enclosure Science \& Technology, BEST 3 conference. Atlanta (USA), April 2012, https://escholarship.org/uc/item/0t68701n

Hoyt T., Arens E., Zhang H. (2015). Extending air temperature setpoints. Simulated energy savings and design considerations for new and retrofit buildings. 1st International Symposium on Sustainable Healthy Buildings 88: pp. 89-96.

Huizenga C., Zhang H., et al. (2001). A model of human physiology and comfort for assessing complex thermal environments. Building and Environmental Performance Simulation:Current State and Future Issues. Building and Environment 36: pp. 691-699.

Kimmling M., Hoffmann S. (2016). Development of a PV-powered thermoelectric partition for userindividual radiative cooling in office buildings, Proceedings of the World renewable energy conference (WREC). Jakarta (Indonesia), September 2016.
Kimmling M., Hoffmann S. (2017a). Influence of PVpowered thermoelectric surfaces for user-individual radiative cooling on the cooling energy demand of buildings. Energy Procedia 132, 15-20.

Kimmling M., Hoffmann S. (2017b). Preliminary study of thermal comfort in buildings with PV-powered thermoelectric surfaces for radiative cooling. Energy Procedia 121, 87-94.

Ladybug Tools. Ladybug Tools. https://www.ladybug.tools/.

Luo M., Arens E., Zhang H., et al. (2018). Thermal comfort evaluated for combinations of energyefficient personal heating and cooling devices. Building and Environment 143, 206-216.

Rida M., Hoffman S. (2019). Using a Dynamic Clothing Insulation Model in Building Simulation - Impact on Thermal Comfort and Energy Consumption. submitted in: IBPSA Italy, Conference Proceedings IBPSA Italy. Rome (Italy), September 2019. (submitted)

Stolwijk J.A.J. (1971). A mathematical model of physiological temperature regulation in man. NASA Contractor report, NASA CR-1855. Washington, D.C.

Tanabe S., Kobayashi K., Nakano J., et al. (2002). Evaluation of thermal comfort using combined multinode thermoregulation (65MN) and radiation models and computational fluid dynamics (CFD). Special Issue on Thermal Comfort Standards 34, 637-646.

Tanabe S., Narita C., Ozeki Y., et al. (2000). Effective radiation area of human body calculated by a numerical simulation. Special Issue on Thermal Comfort Standards 32, 205-215.

Zhang H. (2003). Human thermal sensation and comfort in transient and non-uniform thermal environments. Ph.D. Thesis: University of California, Berkeley (USA).

Zhang H., Arens E., Huizenga C., et al. (2010a). Thermal sensation and comfort models for non-uniform and transient environments, part II: Local comfort of individual body parts. 1st International Symposium on Sustainable Healthy Buildings 45, 389-398.

Zhang H., Arens E., Huizenga C., et al. (2010b). Thermal sensation and comfort models for non-uniform and transient environments, part III: Whole-body sensation and comfort. 1st International Symposium on Sustainable Healthy Buildings 45, 399-410.

Zhang H., Arens E., Huizenga C., et al. (2010c). Thermal sensation and comfort models for non-uniform and transient environments: Part I: Local sensation of individual body parts. 1st International Symposium on Sustainable Healthy Buildings 45, 380-388. 